\title{
Sensitivity of the near - to - maturity European options: comparison of the Carr-Madan approach with a new method based on the Fourier transform
}

\author{
Arkadiusz Orzechowski*
}

\begin{abstract}
Purpose - Analysis of the sensitivity of the valuation of the near - to - maturity European options (performed via the Fourier transform) on the parameter alpha and other risk factors.

Design/methodology/approach - Research is based on an analysis of the sensitivity of the differences between the prices of the European options in the Black-Scholes framework with the theoretical values of the contracts generated by two methods based on the Fourier transform on the changes of different factors.

Findings - The Black-Scholes model is better than other approaches based on the Fourier transform. Despite this, in the case of some models, e.g. stochastic volatility models, methods based on the Fourier transform, e.g. the Carr-Madan method or a new method proposed in the article, must be applied.

Originality/value - An analysis of the sensitivity of the valuation of the near - to - maturity European options to different factors using two methods based on the Fourier transform (including one discovered by the author of the article).
\end{abstract}

Keywords: Fourier transform, Carr-Madan method, option pricing

\section{Introduction}

Options are used to speculate and to hedge against the price risk of an underlying asset. Because of their flexibility and diversity these instruments are willingly traded both on exchanges and the over-the-counter market.

The present article deals with the valuation of the near-to-maturity European options with the use of the Carr-Madan method (Carr, Madan, 1999) and a new method based on the Fourier transform (Orzechowski, 2016). These approaches differ much from the traditional ways of pricing contingent claims. As a result of the fact that they are based on the Fourier transforms, they are considered to be more complex. On the other hand they are said to be more universal.

The aim of the article is a careful examination of both methodologies of pricing European options that are close to expiration and an analysis of their sensitivities to changes in risk factors.

\footnotetext{
* dr Arkadiusz Orzechowski, Szkoła Główna Handlowa w Warszawie, al. Niepodległości 162, 02-554 Warszawa, e-mail: aorzec@sgh.waw.pl.
} 
The paper consists of several sections. At the beginning two techniques of pricing options are presented. The first is based on the solution of the partial differential equation of the second order; the other refers to the so-called martingale method. Next, it discusses methodology, sensitivity and problems related to the calculation of model price of the European options with the use of both the Carr-Madan and the new methods. Particular attention is devoted to the near-to-maturity contracts.

\section{Selected methods of pricing options}

In the financial literature two main approaches may be applied to the valuation of options. The first, developed by F. Black and M. Scholes (1973), is based on a number of simplifying assumptions leading to the formulation of the second order partial differential equation, so called the Black-Scholes PDE. After lengthy transformations of the equation, the following formula for the price of the European call can be obtained (the method is referred to as BS):

$$
C\left(S_{T}, T\right)=S_{0} N\left(d_{1}\right)-K e^{-r T} N\left(d_{2}\right)
$$

where: $S_{0}$ is the initial value of the underlying asset, $K$ is the exercise price of the option, $r$ is the risk-free rate and $N\left(d_{1}\right)$ and $N\left(d_{2}\right)$ are the cumulative distribution functions of the normal distribution with parameters $d_{1}$ and $d_{2}$ respectively, i.e.:

$$
\begin{gathered}
d_{1}=\frac{\ln \left(\frac{S_{T}}{K}\right)+\left(r+\frac{1}{2} \sigma^{2}\right) T}{\sigma \sqrt{t}} \\
d_{2}=d_{1}-\sigma \sqrt{T}
\end{gathered}
$$

where: $S_{T}$ is the market price of the underlying asset at the time of expiration of the contract and $\sigma$ is the standard deviation of the underlying asset' returns.

The second method, called the martingale method (the method is referred to as BS-M), originally proposed by J.C. Cox and S.A. Ross (1976) and J. M. Harrison and D. Krebs (1979), refers to the general scheme of pricing shares, bonds, etc. According to the scheme price of the option is equal to the expected value of future payoffs generated by the instrument discounted with the risk-free rate under certain martingale measure $\tilde{q}$. More formally, prices of the European calls and puts respectively can be calculated with the use of the following formulas:

$$
C\left(S_{\tau}, \tau\right)=e^{-r t} E^{\tilde{q}}\left(\left(S_{T}-K, 0\right)^{+} \mid \Omega_{\tau}\right)
$$




$$
P\left(S_{\tau}, \tau\right)=e^{-r t} E^{\tilde{q}}\left(\left(K-S_{T}, 0\right)^{+} \mid \Omega_{\tau}\right)
$$

Alternatively, it can be written that:

$$
\begin{aligned}
& C\left(S_{\tau}, \tau\right)=e^{-r t} \int_{K}^{\infty}\left(S_{T}-K\right) \tilde{q}\left(S_{T} \mid \Omega_{\tau}\right) d S_{T} \\
& P\left(S_{\tau}, \tau\right)=e^{-r t} \int_{0}^{K}\left(K-S_{T}\right) \tilde{q}\left(S_{T} \mid \Omega_{\tau}\right) d S_{T}
\end{aligned}
$$

where: $\tilde{q}\left(. \mid \Omega_{\tau}\right)$ is the probability density function dependent on filtration $\Omega_{\tau}$ and $t=T-\tau$.

If $S_{T}$ is a random variable with the following probability density function:

$$
\tilde{q}\left(S_{T}\right)=\frac{1}{S_{T} \sigma \sqrt{2 \pi t}} \exp \left\{-\frac{\left[\ln S_{T}-\left(\ln S_{\tau}+\left(r-\frac{1}{2} \sigma^{2}\right) t\right)\right]^{2}}{2 \sigma^{2} t}\right\}
$$

where: $0 \leq \tau \leq T$ and $t=T-\tau$ is the time remaining to expiration, then the formulas for the prices of the European calls and puts respectively can be easily found, i.e.:

$$
\begin{aligned}
& C\left(S_{\tau}, \tau\right)=e^{-r t} \int_{K}^{\infty}\left(S_{T}-K\right) \frac{1}{S_{T} \sqrt{2 \pi \sigma^{2} t}} e^{-\frac{\left\{\ln S_{T}-\left(\ln S_{\tau}+\left(r-\frac{1}{2} \sigma^{2}\right) t\right)\right\}^{2}}{2 \sigma^{2} t} d S_{T}} \\
& P\left(S_{\tau}, \tau\right)=e^{-r t} \int_{0}^{K}\left(K-S_{T}\right) \frac{1}{S_{T} \sqrt{2 \pi \sigma^{2} t}} e^{-\frac{\left\{\ln S_{T}-\left(\ln S_{\tau}+\left(r-\frac{1}{2} \sigma^{2}\right) t\right)\right\}^{2}}{2 \sigma^{2} t} d S_{T}}
\end{aligned}
$$

Unlike the above mentioned approaches, there are a number of alternative methods of pricing European options. In one class of methods, the Fourier transform is applied to the valuation of derivatives constructed on the basis of laws whose execution may be demanded by one party from another.

The most noticeable work presenting the application of the Fourier transform to the pricing of contingent claims is the work by G. Bakshi and D. Madan (2000). In their approach both price of the underlying instrument and the exercise price from equation 6 are converted to logarithmic values. Next, the equation is split into two parts. To obtain the theoretical value of the European option each part of the formula is Fourier transformed and reversed. 
An interesting modification of the G. Bakshi and D. Madan approach was proposed by M. Attari (2004). He applied Fubini and residue theorems to merge two integrals from the Black-Scholes style equation into a formula involving a single one-dimensional integration.

Similar, in terms of computational speed and accuracy, is the method developed by D.S. Bates (2006), which assumes that the option can be priced using a discounted cumulative distribution function, substituting the inversion formula for $q(S)$ and integrating the result with respect to $K$.

Alternative concept was developed by A. Lewis (2001), who performed a multiple transformation of equation 6, converted dependent variables to logarithmic values, expressed the value of the option as a convolution of two generalized Fourier transforms and finally applied Plencherel-Parseval identity to obtain the final price of the contracts.

Although the concepts based on the Fourier transform were developed by many authors, e.g. A. Lipton (2002), it was P. Carr and D. Madan who discovered the most often applicable method based on the Fourier transform to pricing both vanilla and exotic options.

\section{Valuation of the European call in the P. Carr and D. Madan method}

To derive a formula for the price of the European call in the Carr-Madan method it is useful to refer to equation 6 and additionally assume that $\tau=0$. In consequence, equation 6 will take the following form:

$$
C_{K}(T)=e^{-r T} \int_{K}^{\infty}\left(S_{T}-K\right) \tilde{q}\left(S_{T} \mid \Omega_{0}\right) d S_{T}
$$

where: $\tilde{q}\left(. \mid \Omega_{0}\right)$ is the probability density function dependent on filtration $\Omega_{0}$.

If a change of variables is performed according to the following scheme: $s_{T}=\ln S_{T}$ and $k=\ln K$, equation 11 can be rewritten as:

$$
C_{k}(T)=e^{-r T} \int_{k}^{\infty}\left(e^{s_{T}}-e^{k}\right) \tilde{q}\left(s_{T} \mid \Omega_{0}\right) d s_{T}
$$

One can easily conclude that for $K \rightarrow 0$ the function $C_{K}(T)$ is not square integrable and the Fourier transform of $C_{K}(T)$ does not exist. The solution of the problem is found by the modification of the function $C_{K}(T)$, i.e.:

$$
C_{k}^{M}(T)=e^{\alpha k} C_{k}(T)
$$

where $\alpha$ is the positive constant.

The calculation of the Fourier transform and its inverse allows to determine the price of the European call, i.e.: 


$$
C_{k}(T)=\frac{e^{-\alpha k}}{2 \pi} \int_{-\infty}^{\infty} e^{-i \xi k} \frac{e^{-r T} \phi_{T}(\xi-(\alpha+1) i)}{\alpha^{2}+\alpha-\xi^{2}+i(2 \alpha+1) \xi} d \xi
$$

where: $\phi_{T}(\xi)$ is the characteristic function of the variable $s_{T}$.

\section{Valuation of the near - to - maturity European calls in the Carr-Madan method}

As an error resulting from the numerical integration of the sub-integral function in equation 14 becomes significant when determining the prices of the near-to-maturity European call, function $z_{T}(k)$ has to be constructed, i.e.:

$$
z_{T}(k)=\left\{\begin{array}{l}
C\left(S_{0}, 0\right)=C\left(S_{0}, 0\right)-\left(S_{0}-K\right)^{+} \text {if } S_{0}<K \\
P\left(S_{0}, 0\right)=P\left(S_{0}, 0\right)-\left(K-S_{0}\right)^{+} \text {if } S_{0}>K
\end{array}\right.
$$

where: $C\left(S_{0}, 0\right)$ and $P\left(S_{0}, 0\right)$ are the prices of the European call and put respectively at time $\tau=0$ and $\alpha$ is the positive constant.

Alternative representation of equation 15 can take the following form:

$$
z_{T}(k)=e^{-r T} \int_{-\infty}^{\infty}\left[\left(e^{k}-e^{s_{T}}\right) 1_{\substack{s_{T}<k, k<0}}+\left(e^{s_{T}}-e^{k}\right) 1_{\substack{s_{T}>k, k>0}}\right] \tilde{q}\left(s_{T} \mid \Omega_{0}\right) d s_{T}
$$

If the function $z_{T}(k)$ is Fourier transformed one can conclude that:

$$
\zeta_{T}(\xi)=\int_{-\infty}^{\infty} e^{i \xi k} z_{T}(k) d k=e^{-r T}\left(\frac{\phi_{t}(0)}{1+i \xi}-\frac{\phi_{t}(-i)}{i \xi}+\frac{\phi_{t}(\xi-i)}{i \xi(1+i \xi)}\right)
$$

Knowing that the characteristic function of $s_{T}$ is expressed by equation 18, i.e.:

$$
\phi_{t}(\xi)=\int_{-\infty}^{\infty} e^{i \xi s_{T}} \tilde{q}\left(s_{T} \mid \Omega_{0}\right) d s_{T}
$$

correct (sic.) formula for the Fourier transform of the function $z_{T}(k)$ is of the form of equation 17.

Finally, the price of the European call can be determined by the calculation of the inverse Fourier transform of the function $\zeta_{T}(\xi)$, i.e.:

$$
z_{T}(k)=\frac{1}{2 \pi} \int_{-\infty}^{\infty} e^{-i \xi k} \zeta_{T}(\xi) d \xi
$$


To eliminate the above mentioned problem P. Carr and D. Madan calculate the modified Fourier transform of $z_{T}(k)$ (the method is referred to as BS-FTTV):

$$
\gamma_{T}(\xi)=\int_{-\infty}^{\infty} e^{i \xi k} \sinh (\alpha k) z_{T}(k) d k=\frac{\zeta(\xi-i \alpha)+\zeta(\xi+i \alpha)}{2}
$$

and then determine its inverse. In consequence, the price of the near-to-maturity European call can be expressed in the following form:

$$
z_{T}(k)=\frac{1}{\sinh (\alpha k)} \frac{1}{2 \pi} \int_{-\infty}^{\infty} e^{-i \xi k} \gamma_{T}(\xi) d \xi=\frac{1}{\sinh (\alpha k)} \frac{1}{2 \pi} \int_{-\infty}^{\infty} e^{-i \xi k} \frac{\zeta(\xi-i \alpha)+\zeta(\xi+i \alpha)}{2} d \xi
$$

\section{Valuation of the European call in the new method}

The new method of pricing the European call (the method is referred to as BS-FTN) can be divided into several steps. Firstly, the price of the underlying asset and the exercise price in equation 11 are converted to logarithmic values. Next, after splitting the obtained equation into two parts, each of them is Fourier transformed. In consequence, the first part of the equation takes the following form:

$$
\Psi_{T}^{1}(\xi)=\int_{-\infty}^{\infty} e^{i \xi k}\left[e^{-r T} \frac{\int_{k}^{\infty} e^{s_{T}} \tilde{q}\left(s_{T} \mid \Omega_{0}\right) d s_{T}}{\int_{-\infty}^{\infty} e^{s_{T}} \tilde{q}\left(s_{T} \mid \Omega_{0}\right) d s_{T}} \int_{-\infty}^{\infty} e^{s_{T}} \tilde{q}\left(s_{T} \mid \Omega_{0}\right) d s_{T}\right] d k
$$

As $\int_{-\infty}^{\infty} e^{s_{T}} \tilde{q}\left(s_{T} \mid \Omega_{t}\right) d s_{T}$ can be both the characteristic function of $s_{T}$ assuming $\xi=-i$, i.e. $\phi(-i)$ and expected value of $S_{T}$, equation 22 can be expressed as:

$$
\Psi_{T}^{1}(\xi)=\frac{S_{0} \phi(\xi-i)}{i \xi \phi(-i)}
$$

The second part of equation, after being Fourier transformed, takes the following form:

$$
\Psi_{T}^{2}(\xi)=\int_{-\infty}^{\infty} e^{i \xi k} \int_{k}^{\infty} e^{k} \tilde{q}\left(s_{T} \mid \Omega_{0}\right) d s_{T} d k=\frac{\phi(\xi-i)}{i \xi+1}
$$

Finally, both Fourier transforms are inverted and the final price of the option is obtained, i.e.:

$$
C\left(S_{0}, 0\right)=\frac{1}{2} S_{0}-e^{-r T} \frac{1}{\pi} \int_{0}^{\infty} \Re\left[e^{-i \xi k} \frac{\phi(\xi-i)}{i \xi(i \xi+1)}\right] d \xi
$$




\section{Sensitivity of the near-to-maturity European options}

According to P. Carr and D. Madan application of the BS-FTTV method to the pricing of European options allows avoiding oscillations of the subintegral function in equation 21. To make sure that it is true, sensitivities of the differences between call prices calculated by the BS and the BS-FTTV methods to the parameter $\alpha$ and all of the risk factors are determined. In the calculations, it is assumed that the prices of the underlying assets are at the level of 40, 60 and 80 respectively for the out-of-the-money (OTM), at-the-money (ATM) and in-the-money (ITM) options, the exercise price is 60 , the free-risk rate amounts to $5 \%$ and the standard deviation of the underlying asset' returns amounts to 0.2. All results (presented in the figures below) are obtained via numerical integration with the use of codes written in the package Mathematica 8.0.

Based on Figures 1-3 one can draw two conclusions. According to the first one, problems associated with the numerical integration of the inverse Fourier transform in equation 21 appear mainly for the near-to-maturity OTM and ITM options which theoretical prices are calculated with the use of high values of the parameter $\alpha$. The second conclusion refers to the increase in differences between the prices calculated by the BS and the BS-FTTV methods for ITM options as the period becomes more distant from expiration.
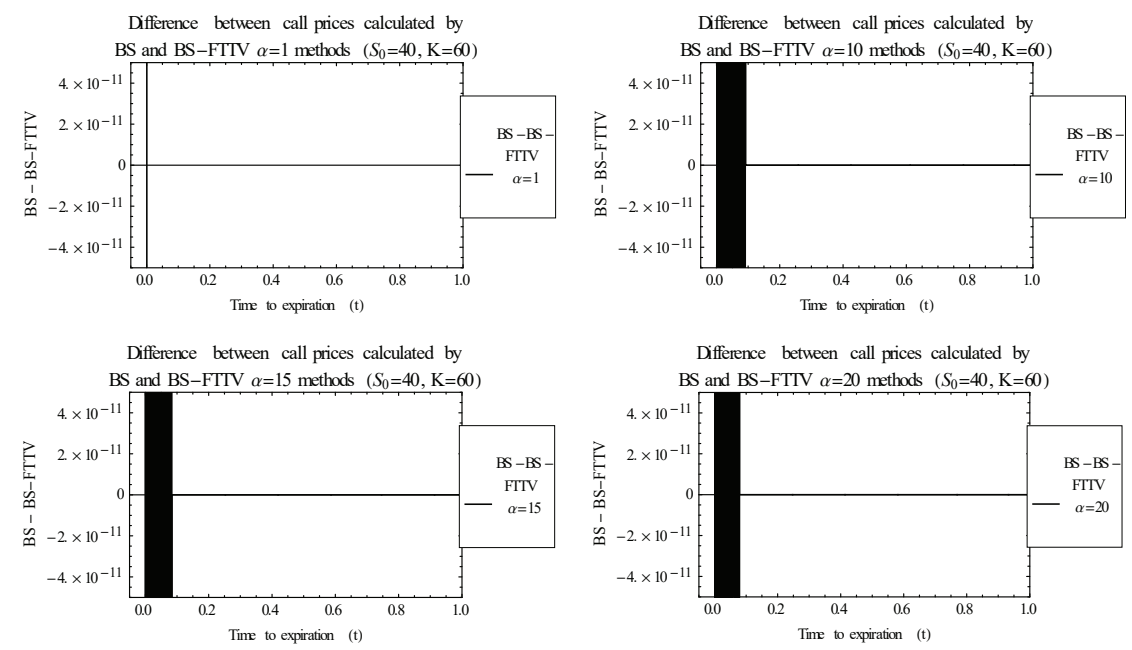

Figure 1. Differences between OTM call prices calculated by BS and BS-FTTV methods for different values of the parameter $\alpha$

Source: own study. 

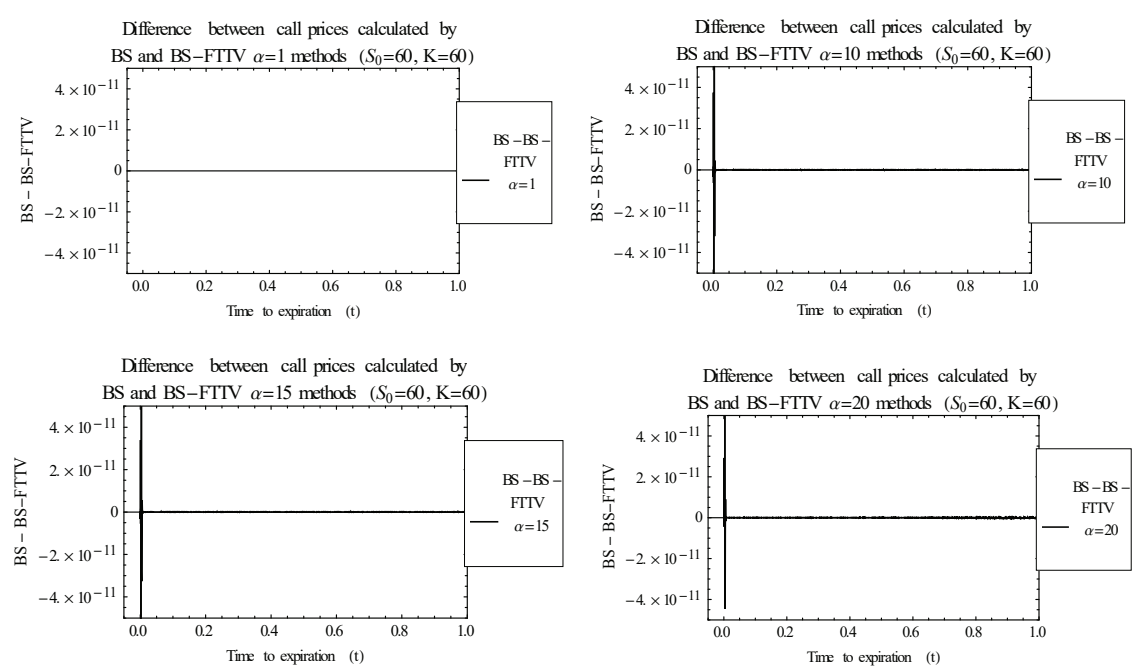

Figure 2. Differences between ATM call prices calculated by the BS and BS-FTTV methods for different values of the parameter $\alpha$

Source: own study.
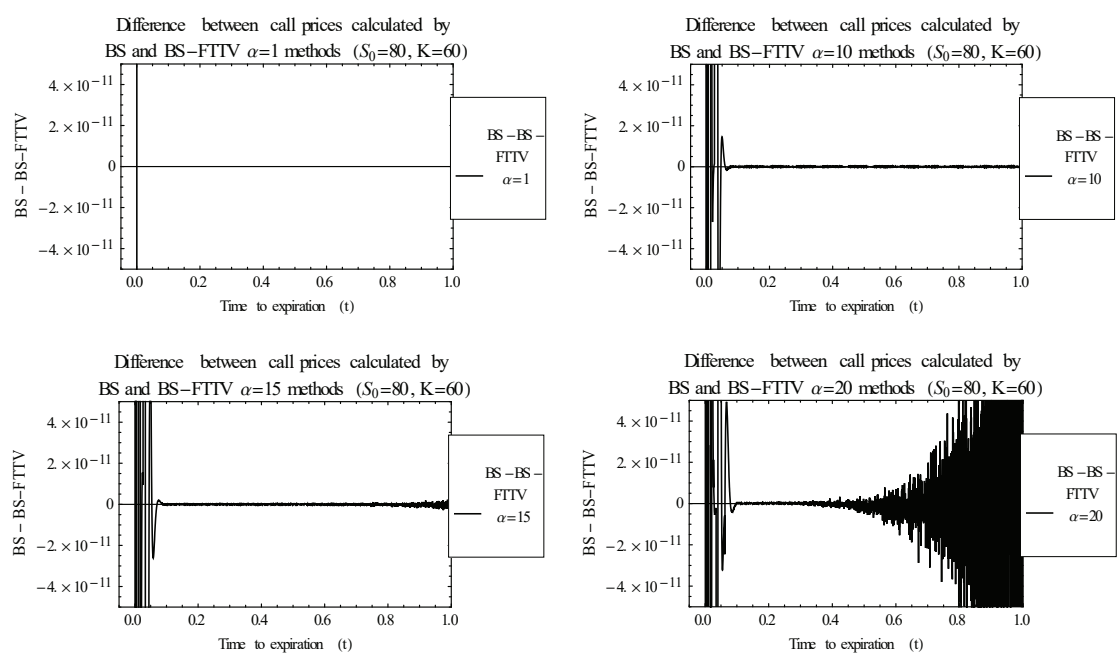

Figure 3. Differences between ITM call prices calculated by BS and BS-FTTV methods for different values of the parameter $\alpha$

Source: own study. 
As it cannot be forgotten that other determinants can exert an impact on the results their influence should be carefully investigated (see the figures below).
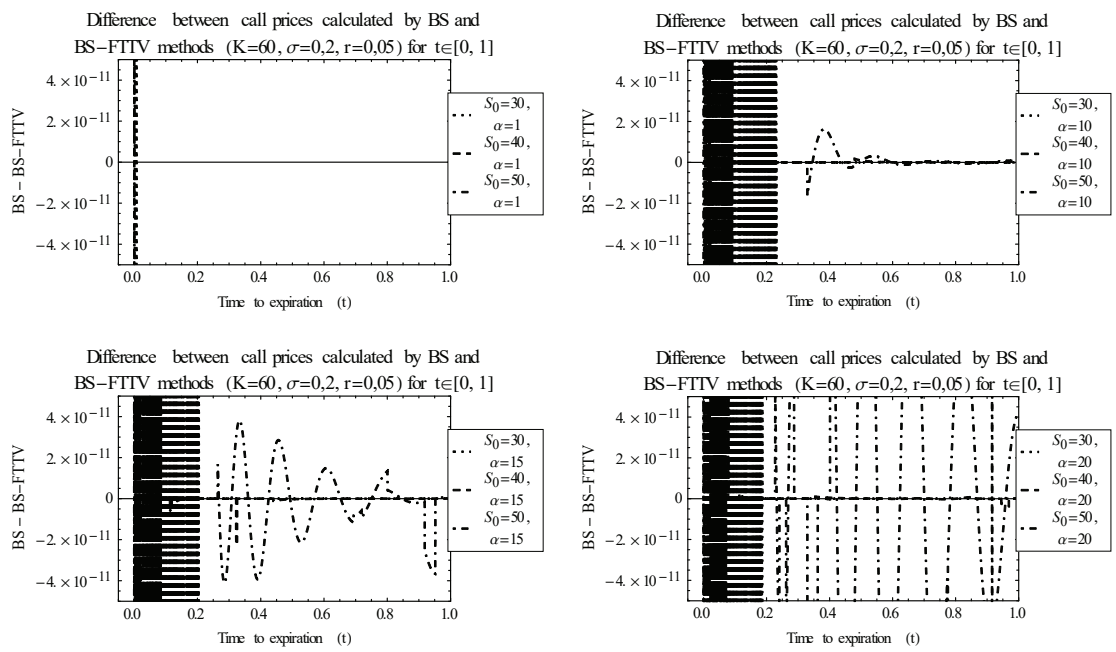

Figure 4. Differences between OTM call prices calculated by BS and BS-FTTV methods for different values of the parameter $\alpha$ and the price of the underlying asset

Source: own study.
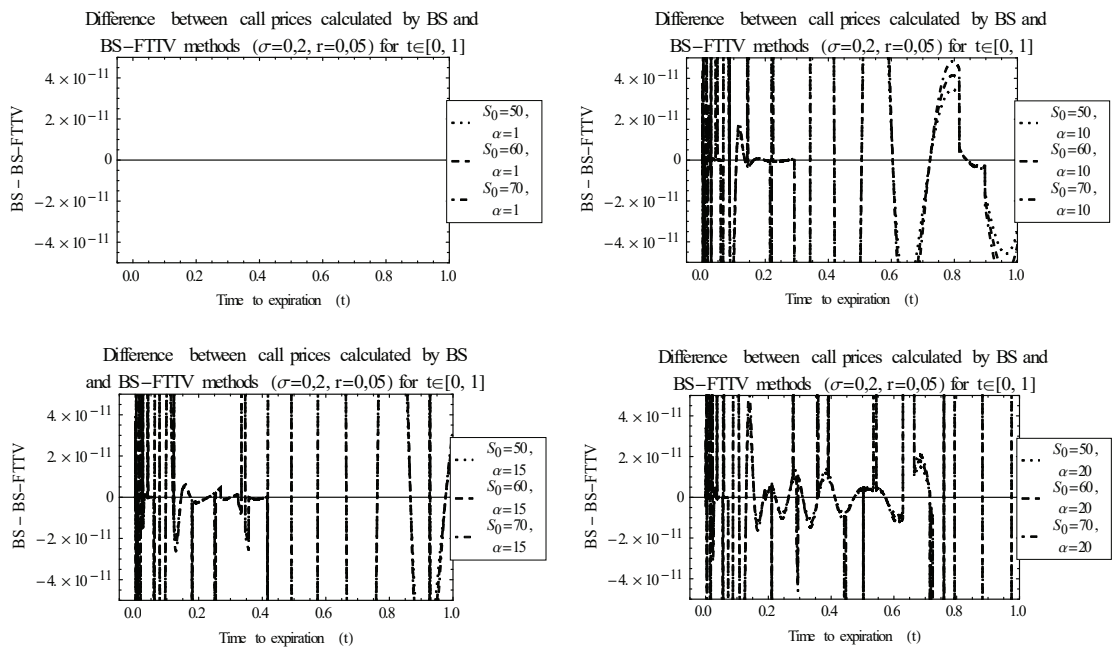

Figure 5. Differences between ATM call prices calculated by BS and BS-FTTV methods for different values of the parameter $\alpha$ and the price of the underlying asset

Source: own study. 

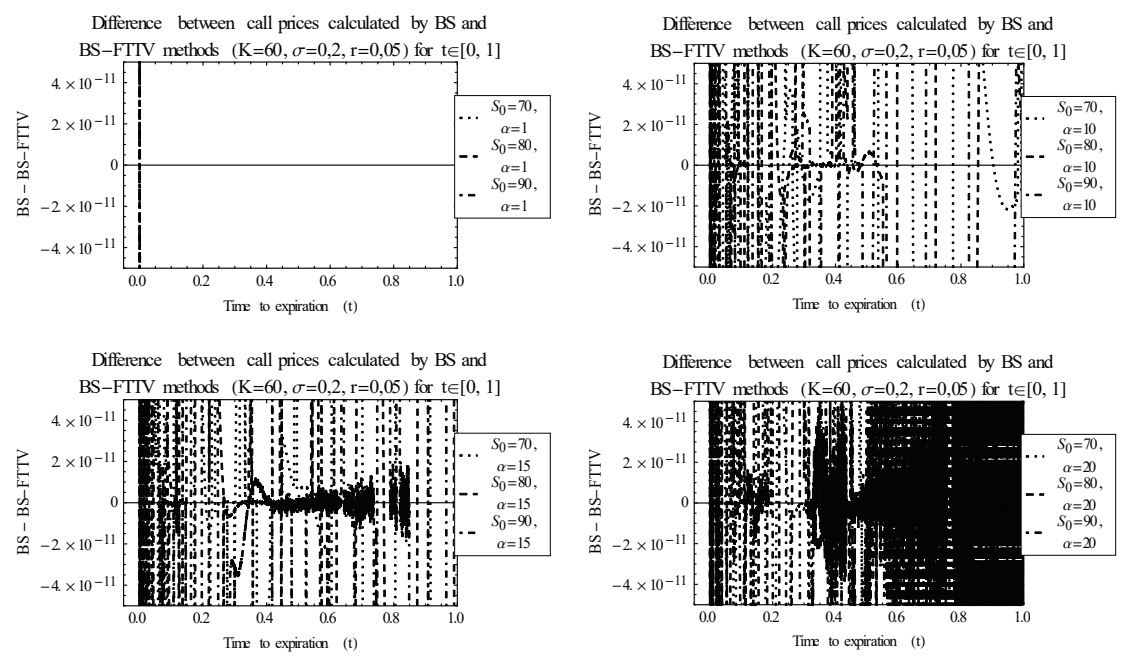

Figure 6. Differences between ITM call prices calculated by BS and BS-FTTV methods for different values of the parameter $\alpha$ and the price of the underlying asset

Source: own study.
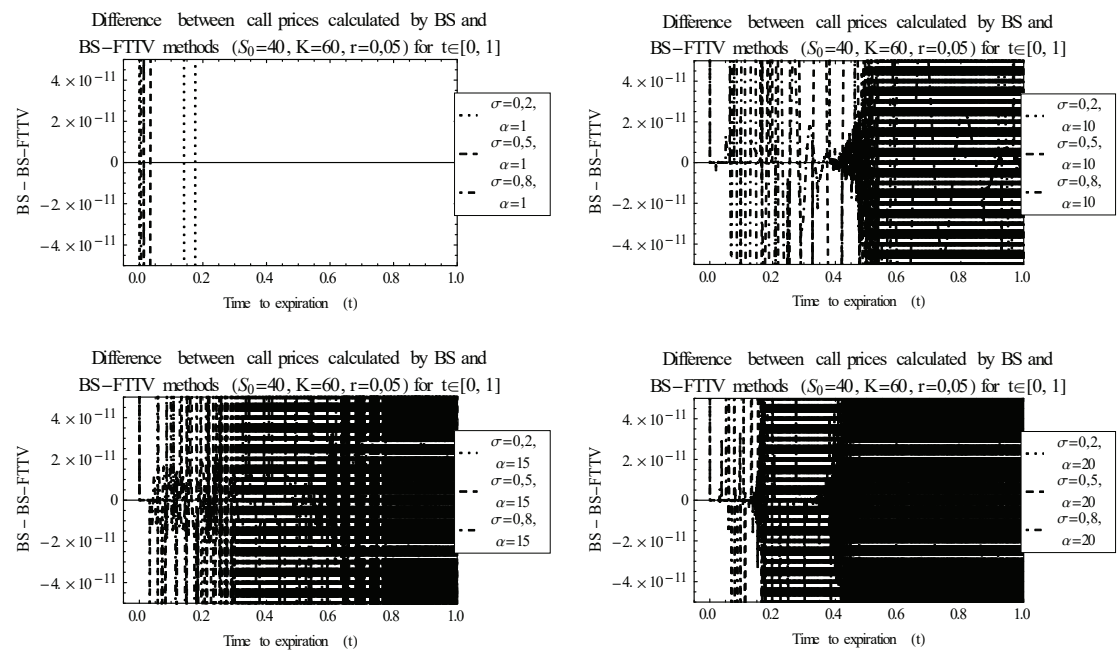

Figure 7. Differences between OTM call prices calculated by the BS and BS-FTTV methods for different values of the parameter $\alpha$ and the variability of the underlying asset

Source: own study. 

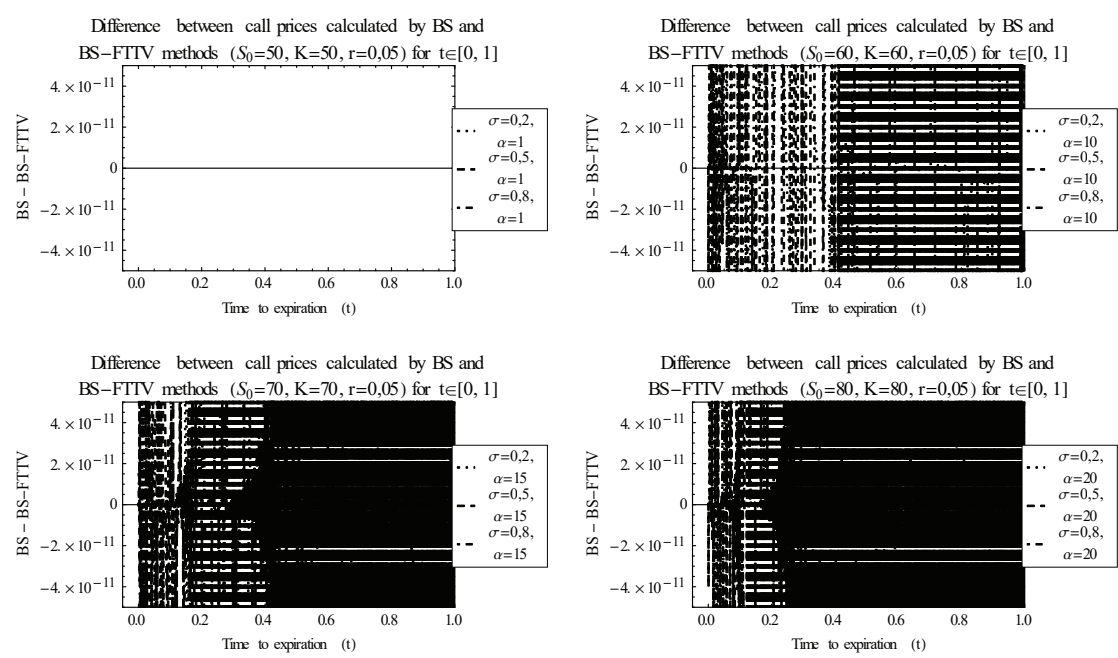

Figure 8. Differences between ATM call prices calculated by the BS and BS-FTTV methods for different values of the parameter $\alpha$ and the variability of the underlying asset

Source: own study.
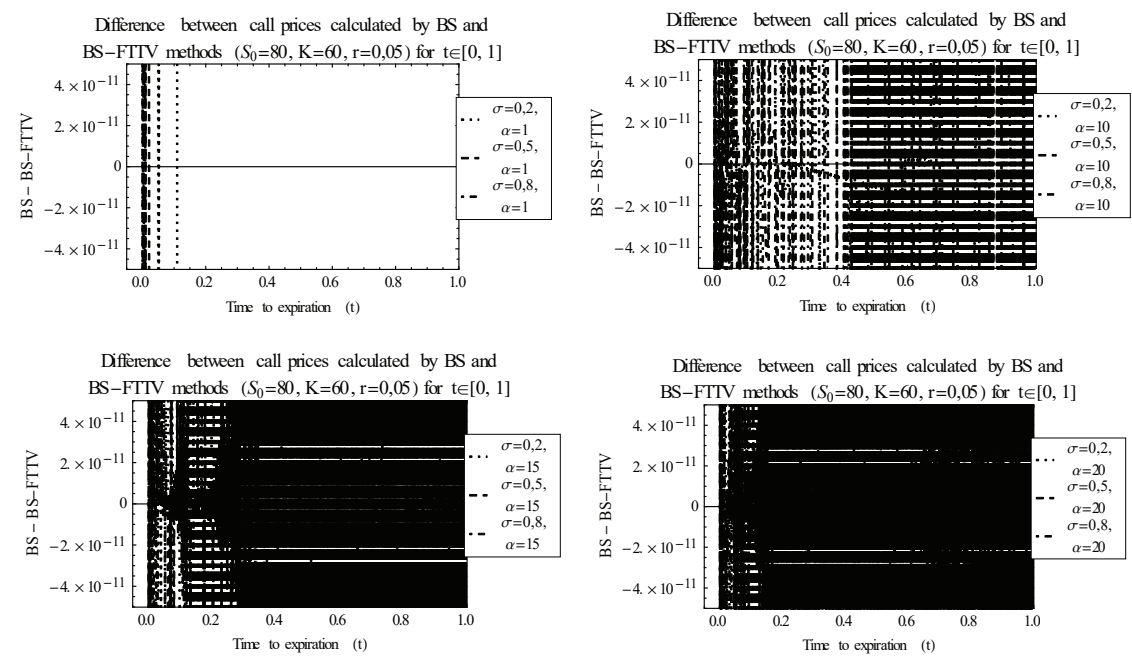

Figure 9. Differences between ITM call prices calculated by the BS and BS-FTTV methods for different values of the parameter $\alpha$ and the variability of the underlying asset

Source: own study. 

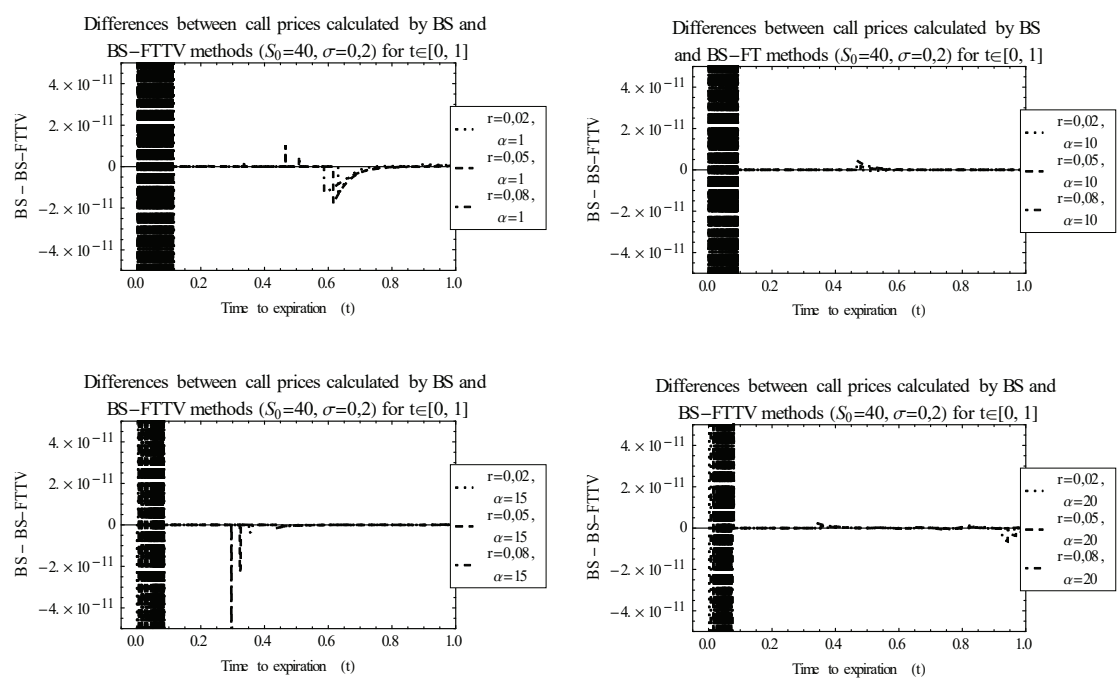

Figure 10. Differences between OTM call prices calculated by BS and BS-FTTV methods for different values of the parameter $\alpha$ and the risk-free rate

Source: own study.
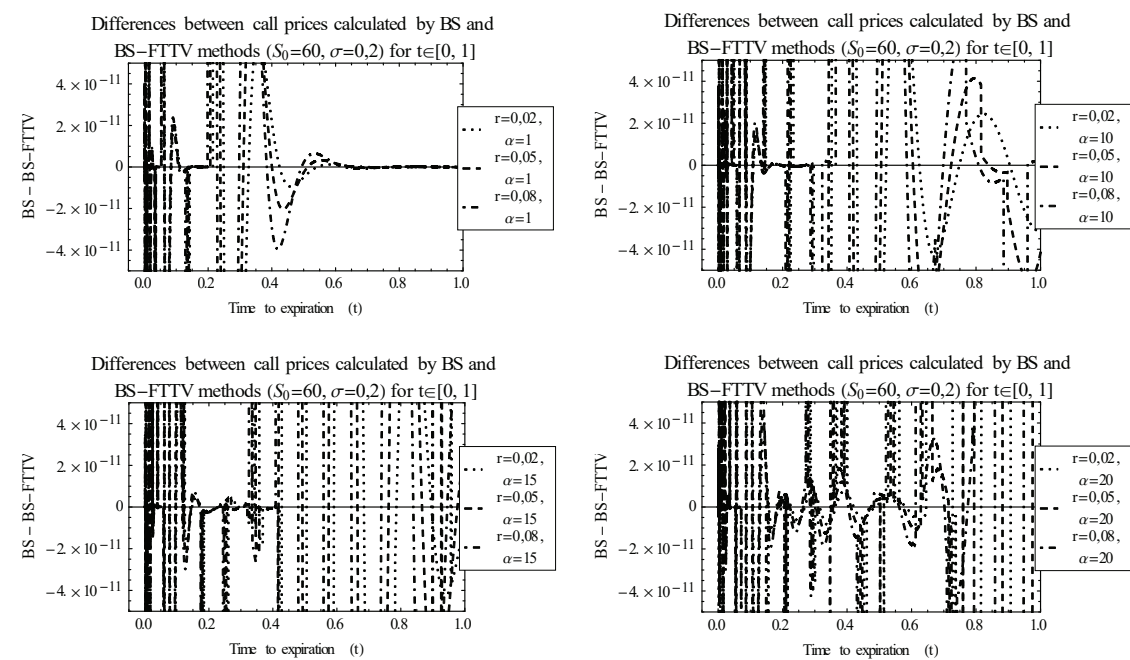

Figure 11. Differences between ATM call prices calculated by the BS and BS-FTTV methods for different values of the parameter $\alpha$ and the risk-free rate

Source: own study. 

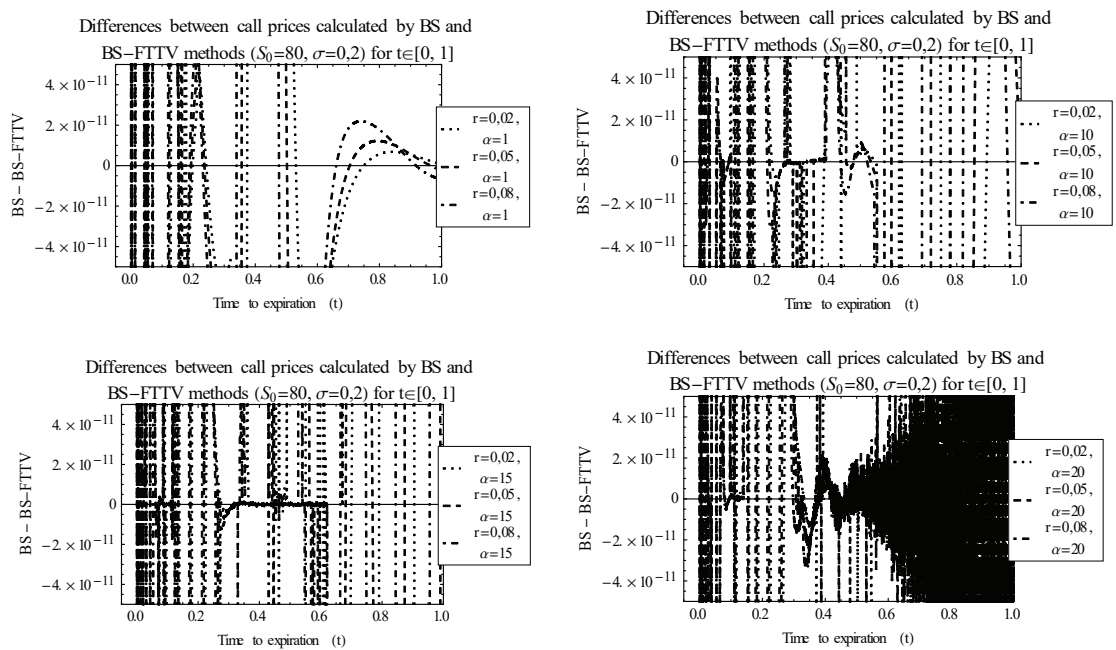

Figure 12. Differences between ITM call prices calculated by the BS and BS-FTTV methods for different values of the parameter $\alpha$ and the risk-free rate

Source: own study.

The most important results that were obtained can be divided into three groups depending on the type of analysed contracts. For the OTM options the following regularities may be observed:

a) the more the contracts remain OTM, as they approach the moment of expiration, the bigger the differences between the BS and the BS-FTTV valuations;

b) the higher the parameter $\alpha$, the worse the accuracy of the BS-FTTV method;

c) the higher the standard deviation of the rate of return of the underlying assets, the worse the accuracy of the valuation of options based on the numerical calculation of the inverse Fourier transform (especially in the periods close to the date of issuance of the contingent claims).

For the ATM options the following relationships are observed:

a) as the volatility of the underlying instrument increases, the time of issuance of options approaches and the risk-free rate grows, the divergence of valuations resulting from the application of the BS and the BS-FTTV methods becomes more conspicuous;

b) the higher the parameter $\alpha$, the bigger the oscillations of the subintegral function in equation 21.

For the ITM options the following relationships are observed:

a) as the parameter $\alpha$ grows and time approaches to the date of expiration of the problems with numerical integration become more significant;

b) variability of the underlying instrument has a negative impact on the accuracy of the valuation in the BS-FTTV method; 
c) the closer the options are to ITM and the closer the date of expiration, the greater problems with numerical integration appear.

In the second approach the parameter $\alpha$ does not exist which means that only sensitivities of the difference between call prices calculated by the BS and the BS-FTN methods to risk factors can be determined. In further calculations, assumptions concerning the prices of underlying assets, the exercise price, the risk-free rate and the standard deviation are the same as previously. All results are again obtained numerically with the use of codes written in package Mathematica 8.0. The generated results are presented in the figures below.

As previously, the obtained results can be divided into three groups depending on the type of the analysed contracts. For OTM options the following statements become true:

a) the deeper the contracts are OTM, as they approach the moment of expiration, the more significant are the differences between the BS and the BS-FTN valuations;

b) the higher the standard deviation of the rate of return of the underlying assets, the worse the precision of the valuation of options based on the Fourier transform technique.

For the ATM options the following relationship can be noticed:

a) as the variability of the underlying instrument increases, the time of issuance of options approaches and the risk-free rate grows, the divergence of the valuations resulting from the application of the BS and the BS-FTN methods becomes more conspicuous.
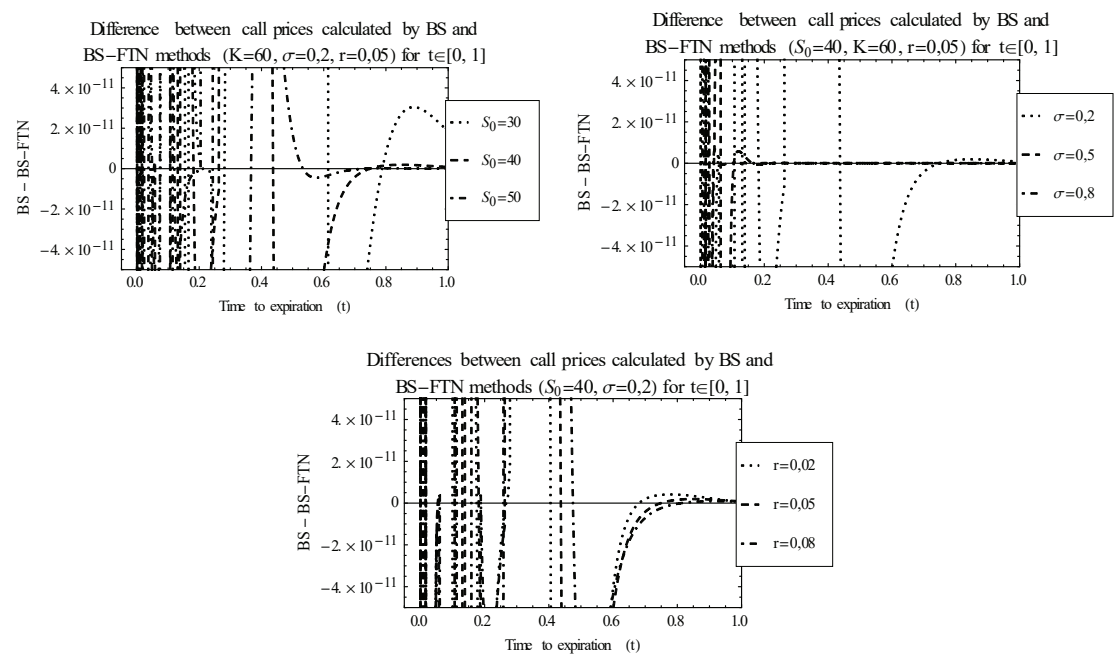

Figure 13. Differences between OTM call prices calculated by the BS and BS-FTN methods for different risk factors

Source: own study. 

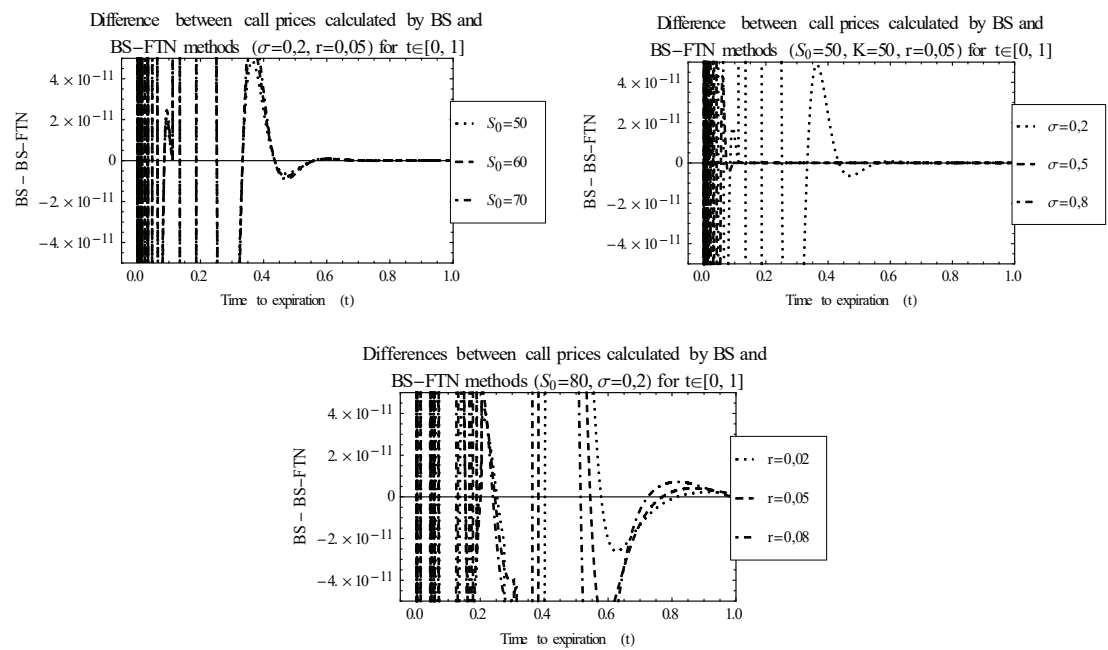

Figure 14. Differences between ATM call prices calculated by the BS and BS-FTN methods for different risk factors

Source: own study.
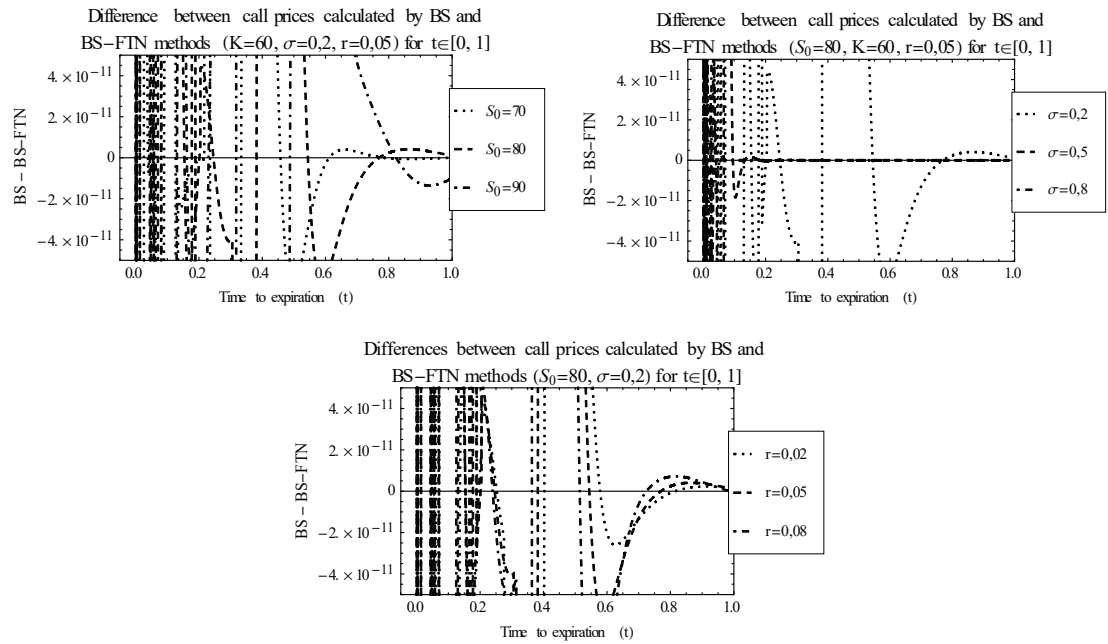

Figure 15. Differences between ITM call prices calculated by the BS and BS-FTN methods for different risk factors

Source: own study. 
For ITM options the following relationships are observed:

a) volatility of the underlying instrument has an adverse influence on the accuracy of the valuation in the BS-FTN method;

b) the closer the options are ITM and the closer the date of expiration, the greater problems with numerical integration appear.

\section{Conclusions}

This article presents the results of research concerning the valuation of the near-to-maturity European options priced with the use of Carr-Madan and new methods. It is extremely important that the methods can be easily applied to different models of the valuation of contingent claims and different types of contracts, i.e. vanilla and exotic options.

Although there are many possibilities of applying the BS-FTTV and the BS-FTN methods to the valuation of options, the BS methodology is most often used in practice. This is due to the following facts:

a) the BS-FTTV and the BS-FTN methods generate theoretical prices of the options slower than the standard model developed by F. Black and M. Scholes;

b) precision of the BS method is greater than the BS-FTTV and the BS-FTN techniques;

c) unlike the BS method, precision of the BS-FTTV approach is sensitive to the parameter $\alpha$ and other risk factors.

Although it seems that the analysed methodology of pricing contingent claims cannot be an interesting alternative for the BS method, it has a wide application in other models of pricing options, e.g. jump diffusion models (Duffie et al., 2000), pure jump models (Madan et al., 1998) and the most advanced models of pricing options, i.e. stochastic volatility models (Heston, 1993; Stein, Stein, 1991). In the latest case standard approach, i.e. the BS method cannot be used. For that reason the optimal choice of the Fourier transform scheme for the valuation of the European options becomes a vital issue.

It cannot be also forgotten that the methodology based on the Fourier transform can be applied both to pricing vanilla and exotic options (Zhu, 2000).

\section{References}

Attari, M. (2004). Option pricing using Fourier transform: a numerically efficient simplification. Retrieved from: https://papers.ssrn.com/sol3/papers.cfm?abstract_id=520042 (8.12.2017).

Bakshi, G., Madan, D. (2000). Spanning and derivative - security valuation. Journal of Financial Economics, 2 (55), 205-238. DOI: 10.1016/S0304-405X(99)00050-1.

Bates, D.S. (2006). Maximum likelihood estimation of latent affine processes. Review of Financial Studies, 3 (19), 909-965. DOI: 10.1093/rfs/hhj022.

Black, F., Scholes, M. (1973). The pricing of options and corporate liabilities. Journal of Political Economy, 3 (81), 637-654. DOI: 10.1086/260062.

Carr, P., Madan, D. (1999). Option valuation using the fast Fourier transform. Journal of Computational Finance, 2 (4), 61-73. DOI: 10.21314/JCF.1999.043. 
Cox, J.C., Ross, S.A. (1976). The valuation of options for alternative stochastic processes. Journal of Financial Economics 1-2 (32), 145-166. DOI: 10.1016/0304405X(76)90023-4.

Duffie, D., Pan, J., Singleton, K. (2000). Transform analysis and asset pricing for jump-diffusions. Econometrica, 6 (68), 1343-1376. DOI: 10.1111/1468-0262.00164.

Harrison, J.M., Krebs, D. (1979). Martingales and arbitrage in multiperiod securities markets. Journal of Economic Theory, 20, 183-191.

Heston, S. (1993). A closed-form solution for options with stochastic volatility with applications to bond and currency options. The Review of Financial Studies, 2 (6), 327-343. DOI: 10.1093/rfs/6.2.327.

Lewis, A. (2001). A simple option formula for general jump-diffusion and other exponential Levy processes. SSRN Electronic Journal, 1-25. DOI: 10.2139/ssrn.282110.

Lipton, A. (2002). The Vol Smile Problem. Retrieved from: http://www.math.ku.dk/ rolf/Lipton_VolSmileProblem. pdf (8.12.2017).

Madan, D., Carr, P., Chang, E. (1998). The variance gamma process and option pricing. European Finance Review $l$ (2), 79-105. DOI: https://doi.org/10.1023/A:1009703431535.

Orzechowski, A. (2016). Analiza efektywności obliczeniowej opcji na przykładzie modelu F. Blacka i M. Scholesa, Finanse, 1 (9), 137-154.

Stein, E.M., Stein, J.C. (1991). Stock price distribution with stochastic volatility: An analytic approach. The Review of Financial Studies, 4 (4), 727-752. DOI: 10.1093/rfs/4.4.727.

Zhu, J. (2000). Modular pricing of options: An application of Fourier analysis. Lecture Notes in Economics and Mathematical Systems 493. Berlin, Heidelberg: Springer-Verlag. DOI: 10.1007/978-3-662-04309-7.

\section{ANALIZA WRAŻLIWOŚCI WYCENY OPCJI EUROPEJSKICH BLISKICH WYGAŚNIĘ- CIA: PORÓWNANIE METODY CARRA-MADANA Z NOWYM PODEJŚCIEM OPARTYM NA TRANSFORMACIE FOURIERA}

Streszczenie: $\mathrm{Cel}$ - Analiza wrażliwości wyceny opcji europejskich bliskich wygaśnięcia (dokonywanej za pomocą transformaty Fouriera) na parametr alfa oraz inne czynniki ryzyka.

Metodologia - Badania oparte są na analizie wrażliwości różnic pomiędzy cenami opcji europejskich w modelu Blacka-Scholesa a wartościami teoretycznymi będących przedmiotem zainteresowania kontraktów wyznaczanych przy wykorzystaniu podejść opartych na transformacie Fouriera na zmiany poszczególnych czynników ryzyka.

Wynik - Model Blacka-Scholesa jest lepszy niż inne podejścia oparte na transformacie Fouriera. Pomimo tego, w przypadku niektórych modeli, np. modeli stochastycznej zmienności, należy stosować metody oparte na transformacie Fouriera (np. metodę Carra-Madana lub nową metodę zaproponowaną w niniejszym artykule).

Oryginalność - Analiza wrażliwości wyceny opcji europejskich bliskich wygaśnięcia na różne czynniki w dwóch podejściach do wyceny opcji opartych na transformacie Fouriera (w tym jednym opracowanym przez autora artykułu).

Słowa kluczowe: transformata Fouriera, metoda Carra-Madana, wycena opcji

\section{Citation}

Orzechowski, A. (2018). Sensitivity of the near - to - maturity European options: comparison of the Carr-Madan approach with a new method based on the Fourier transform. Finanse, Rynki Finansowe, Ubezpieczenia, 1 (91), 483-499. DOI: 10.18276/frfu.2018.91-39. 
